\title{
Comparison of Deficiency and Toxicity of Copper Between Human and Crop Plants: A Review and Some Notes
}

\author{
Chee Kong Yap ${ }^{1 *}$, Shih Hao Tony Peng ${ }^{2}$, Chee Wah Yap ${ }^{3}$, Rosimah Nulit ${ }^{1}$ and Uma Rani Sinniah ${ }^{4}$ \\ ${ }^{1}$ Department of Biology, Faculty of Science, Universiti Putra Malaysia, Serdang, Selangor, Malaysia \\ ${ }^{2}$ All Cosmos Bio-Tech Holding Corporation, PLO650, Jalan Keluli, Pasir Gudang Industrial Estate, Johor, Malaysia \\ ${ }^{3}$ MES SOLUTIONS, Selangor, Malaysia \\ ${ }^{4}$ Faculty of Agriculture, University Putra Malaysia, Serdang, Selangor, Malaysia
}

*Corresponding Author: Chee Kong Yap, Department of Biology, Faculty of Science, Universiti Putra Malaysia, Serdang, Selangor, Malaysia.

Received: November 08, 2019; Published: November 27, 2019

DOI: $10.31080 /$ ASNH.2019.03.0558

\begin{abstract}
The review on Copper (Cu) of its Deficiency and Toxicity (DAT) has been reported on human and plants but there are definite differences and similarities of $\mathrm{Cu}$ deficiency and toxicity between human and plants which remains to be poorly understood. In this review, similarities and differences of $\mathrm{Cu}$ deficiency and excess between human and plants are found. The similarities include any deficient or excessive levels of $\mathrm{Cu}$ can potentially produce harmful effects on human health and reducing vegetative growth ending with toxic effects in plants. The main difference for the dose-response curve of deficient or excessive levels of $\mathrm{Cu}$ is $U$-shaped which is based on cumulative health risk and total intake of $\mathrm{Cu}$ in human consumption while the dose-response curve is $\cap$-shaped which is based on increasing vegetative growth (and yield) and increasing $\mathrm{Cu}$ content in plants. This review can shed some lights on the understanding of $\mathrm{Cu}$ uptake on the health of the crop plant (oil palms) which is comparative to that in human.
\end{abstract}

Keywords: Copper; Deficiency; Excess

\section{Introduction}

The review on Copper $(\mathrm{Cu})$ of its Deficiency and Toxicity (DAT) has been reported on human [1-4] and plants [5,6]. However, there are definite differences and similarities of Cu deficiency and toxicity between human and plants which remains to be poorly understood.

The objective of this review is to compare the Cu DAT between human and plants. This will provide some notes and insights from the monitoring and risk assessment of $\mathrm{Cu}$.

Copper in human

$\mathrm{Cu}$ is an essential trace metal in humans [1,3] for the synthesizing of hemoglobins [7]. $\mathrm{Cu}$ is mostly bound to metalloproteins for detoxification purpose in the form of storage functions in living organisms. Deficiency of Cu can result in harmful toxicological conditions but it can be reversed by adequate $\mathrm{Cu}$ supplementation. The dietary reference intakes and guidelines for $\mathrm{Cu}$ for humans have been well defined [1].

Human Health Risk Assessment (HHRA) for nutrients such as $\mathrm{Cu}$ assumes a single population with a normal distribution of indexes of requirements and excess. Toxic levels can be defined as intakes above the upper level [2]. Elevated $\mathrm{Cu}$ intake by human via the marine seafood consumption can cause harmful health problems including liver and kidney failure but it is not carcinogenic to humans and animals [8]. 
In human, both Cu Deficiency And Excess (DAE) can potentially produce harmful health consequences, the Dose-Response (DR) curve is U-shaped [3] (Figure 1). Stern., et al. [3] proposed a DR modelling strategy for Cu toxicity associated with DAE. The DR modelling strategy is important to understand if the existing toxicity data for Cu DAE may be effectively used in defining the limits of the homeostatic range in humans.

Figure 1 shows the use of nutrient (in this review is $\mathrm{Cu}$ ) intake recommendations in risk assessment in a human population. The distributions of nutrient intakes for a human population have been added to explore risk of deficiency or excess [10-15]. In this model, the proportion of individuals that have nutrient intakes below the Estimated Average Requirement (EAR) are at risk of deficiency, while those exceeding Upper Limit (UL) are at risk of excess. The relevant information regarding the proportion of nutrient intakes in a population group can be found in the reports by FNB [10] and WHO [12].

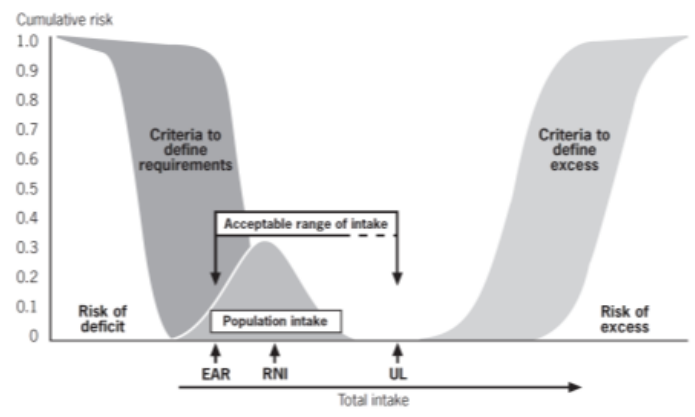

Figure 1: Distribution of human population intakes of nutrients and risks of deficit and excess [9].

Note: $\mathrm{EAR}=$ Estimated average requirement [10-12]; RNI= Recommended nutrient intake [10-12]; UL= Upper limit [13,14].

In the marine seafood, the Maximum Permissible Limit (MPL) for human consumption for Cu suggested by Malaysian Food Regulations 1985 [16] and FAO [17] is $30 \mathrm{mg} / \mathrm{kg}$ wet weight, with the range of the legal limits of $\mathrm{Cu}$ as $20-70 \mathrm{mg} / \mathrm{kg}$ wet weight. Recently, there are many publications in the seafood on human health risk of essential metals have been found in the literature [18-23]. However, the comparisons of MPL with the DR curve as U-shaped is difficult to understand based on current knowledge, needing more clinical and ecotoxicological investigations.

\section{Copper in plants}

Both $\mathrm{Cu}$ DAE can also potentially diminish growth effects, the DR curve is $\mathrm{n}$-shaped (contrasting that in human) in plants (Figure 2) and in Oil Palms (OP) (Figure 3). Likewise, $\mathrm{Cu}$ is an essential metal for plants [5]. It plays crucial roles in respiratory electron transport chains and photosynthesis, oxidative stress protection, ethylene sensing and cell wall metabolism [5]. Thus, a Cu deficiency can change the essential functions in plant metabolism [5].

On the contrary, excessive $\mathrm{Cu}$ exposure ending to high $\mathrm{Cu}$ accumulation in the plant can lead to phytotoxicity by the formation of reactive oxygen radicals that damage cells. The overly high $\mathrm{Cu}$ uptake in plants can disturb the normal interaction with proteins that can damage cellular functions including inactivating enzymes and disturbing protein structure [5].

$\mathrm{Cu}$ excess due to $\mathrm{Cu}$ pollution in the environment can cause problems of growth and yield of food crops such as OP. This can incur public concern from food safety and security threats standpoints [6]. In OP, Cu deficiency instigates stunted new leaves, with reduction of leaflets size and an extensive tip necrosis following the death of the meristem [24,25].

Figure 2 shows the dependence of plant growth and yield dependence on nutrient supply [26]. Almost the same diagram and concept has been outlined by Brady and Weil [27] and Nutrient Management Handbook [28] for plant growths or yields in relation to their excessive and deficient uptake of nutrients in plants.

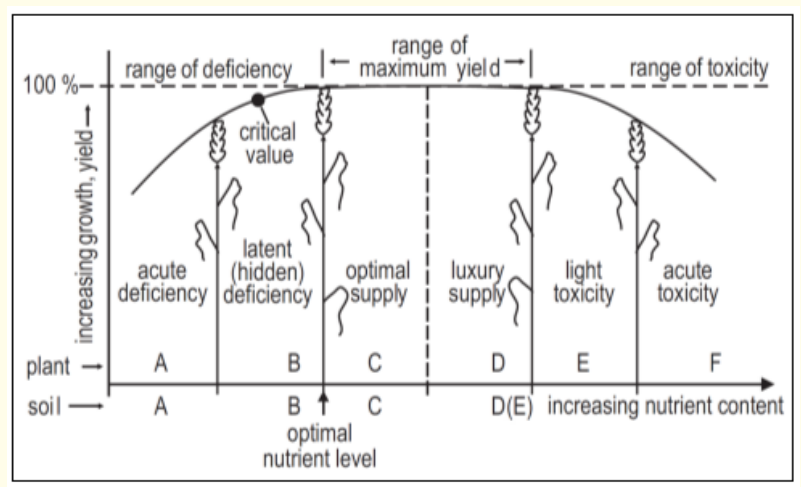

Figure 2: Plant growth and yield dependence on nutrient supply [26]. 
The nutrient status of a plant ranges from acute deficiency to acute toxicity (Figure 2). In general, the nutrient status of the plants can be divided into three groups: deficient, optimal and excess. Acute deficiency is related to definite visible symptoms and poor growth. Its addition can cause an increase in growth and yields. The optimal supply can result in healthy green plants, good growth and high yields. Hence, good quality crop plant can be expected. For the acute toxicity, plants are impaired by toxic nutrient (such as $\mathrm{Cu}$ ) levels causing toxicity symptoms, with poor yield and low quality [26].

In Figure 3, the $\mathrm{n}$-shaped curve of DAE in relation to leaf nutrient concentrations and yield in the OP is like Figure 2. The $\mathrm{Cu}$ DAE in plants is exemplified by using OP trees, as shown in Figure 3 (diagram edited from Hartley [29]). This is because the OP (for example Elaeis guineensisis) can produce the commercial edible vegetable oil which is derived from the mesocarp of the fruit of the OP [30], and the palm oil can produce significant source of fat and a food staple in many cuisines [31]. Based on the original diagram edited from Hartley [29].

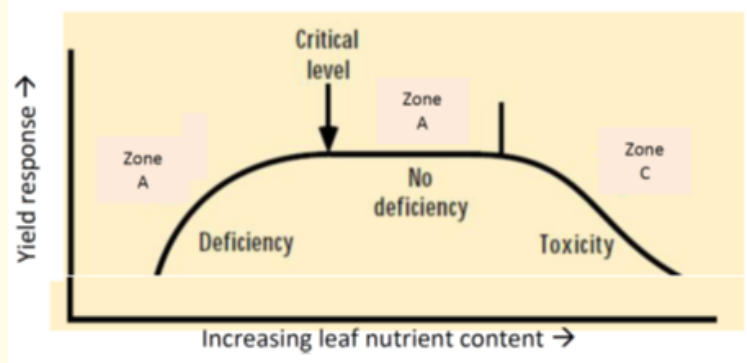

Figure 3: Diagram of deficiency and toxicity in relation to leaf nutrient concentrations and yield in the oil palm [29].

Note

Zone A: Normal growth response with increasing nutrient concentration reaching the 'critical' level or zone.

Zone B: No growth response but increasing nutrient concentration (this further increase does not occur in oil palm).

Zone C: Increasing nutrient concentration with toxic effect.

Between the nutrient concentrations of the deficiency range and those of no deficiency (adequate supply), there is the critical nutrient range as described in Figure 3 [32]. Critical $\mathrm{Cu}$ con- centrations in the case of oil-palm are different for young palms and for older palms have been well established since OP is a cash commodity crop [32,33]. According to the $\mathrm{Cu}$ guideline in leaves of OP of 1-6 years (or > 6 years) after planting suggested by von Uexküll and Fairhurst (1991), the three $\mathrm{Cu}$ concentrations (mg/ $\mathrm{kg}$ ) are 'Deficiency (<3.0)', 'Optimum (5.00-7.00)', and 'Excessive ( $>15.0)$ ', while for the mature OP are 'Deficiency $(<3.0)$ ', 'Optimum (5.00-8.00)', and 'Excessive ( $>15.0$ )'. These $\mathrm{Cu}$ guidelines point to the significance of DAT of $\mathrm{Cu}$. Recently, the HHRA of essential metals (including $\mathrm{Cu}$ ) in the vegetables have been reported in the literature [34-38]. However, HHRA of $\mathrm{Cu}$ has not been established in the palm oil in the literature.

\section{Concluding Remarks}

Similarities and differences of $\mathrm{Cu}$ DAE between human and plants are found. The similarities include any deficient or excessive levels of $\mathrm{Cu}$ can potentially produce harmful effects on human health and reducing vegetative growth ending with toxic effects in plants. The main difference for the DR curve of deficient or excessive levels of $\mathrm{Cu}$ is $\mathrm{U}$-shaped which is based on cumulative health risk and total intake of $\mathrm{Cu}$ in human consumption while the DR curve is $\mathrm{n}$-shaped which is based on increasing vegetative growth (and yield) and increasing $\mathrm{Cu}$ content in plants. This review can shed some lights on the understanding of $\mathrm{Cu}$ uptake on the health of OPs has similar response as in the human.

\section{Bibliography}

1. Fraga CG. Relevance, essentiality and toxicity of trace elements in human health. Molecular Aspects of Medicine 26.4-5 (2005): 235-244.

2. Uauy R., et al. "Estimating risk from copper excess in human populations". The American Journal of Clinical Nutrition 88.3 (2008): 867S-871S.

3. Stern BR., et al. "Copper and human health: biochemistry, genetics, and strategies for modeling dose-response relationships". Journal of Toxicology and Environmental Health Part B, 10.3 (2007): 157-222.

4. Collins JF and Klevay LM. "Copper". Advances in Nutrition 2.6 (2011): 520-522.

5. Yruela I. "Copper in plants: acquisition, transport and interactions”. Functional Plant Biology 36 (2009): 409-430.

6. Adrees M., et al. "The effect of excess copper on growth and physiology of important food crops: a review". Environmental Science and Pollution Research 22.11 (2015): 8148-8162. 
7. Mertz W., et al. "The essential trace elements". Science 213 (1981): 1332-1338.

8. Gorell JM., et al. "Occupational exposures to metals as risk factors for Parkinson's disease". Neurology 48 (1997): 650-658.

9. WHO/FAO. (World Health Organization and Food and Agriculture Organization of the United Nations). Joint FAO/WHO Expert Consultation on Human Vitamin and Mineral Requirements (2004).

10. FNB (Food and Nutrition Board). Dietary reference intakes: applications in dietary assessment. Washington, DC, National Academy Press (2001).

11. WHO (World Health Organization). Energy and protein requirements. Report of a Joint FAO/WHO/UNU Expert Consultation. Geneva, World Health Organization (WHO Technical Report Series (1995).

12. WHO (World Health Organization). Trace elements in human nutrition and health. Geneva, World Health Organization (1996).

13. WHO (World Health Organization). "Principles and methods for the assessment of risk from essential trace elements". Geneva, World Health Organization (Environmental Health Criteria 228) (2002).

14. FNB (Food and Nutrition Board). "Dietary reference intakes. A risk assessment model for establishing upper intake levels for nutrients". Washington, DC, National Academy Press, (1999).

15. Uauy R and Hertrampf E. "Food-based dietary recommendations: possibilities and limitations". In: Bowman B, Russell R, eds. Present knowledge in nutrition, 8th ed. Washington, DC, International Life Sciences Institute Press (2001): 636-649.

16. MFR. Malaysian Food Regulations. Malaysian law on food and drugs. Malaysian Law, Kuala Lumpur (1985).

17. Nauen CE., et al. "Compilation of legal limits for hazardous substances in fish and fishery products". FAO Fisheries Circular 764 (1983): 102.

18. Yap CK. "From Mussel Watch monitoring to health risk assessment: A public health concern". GSL Journal of Public Health and Epidemiology 1 (2017): 103.

19. Yap $\mathrm{CK}$. "A review of $\mathrm{Cd}, \mathrm{Cu}$ and $\mathrm{Zn}$ in cockle Anadara Granosa and mussel Perna Viridis: Comparison of food safety limits and human health risk assessment". SCIOL Biomedicine 2 (2018): 89-101.
20. Yap CK., et al. "Health risk assessments of heavy metal exposure via consumption of marine mussels collected from anthropogenic sites". Science of the Total Environment 553 (2016): 285-296.

21. Yap CK., et al. "Heath risk assessment of heavy metals in shrimp Acetes sp. and cincalok collected in 2007 from Pantai Klebang, Peninsular Malaysia". Journal of Toxicology and Risk Assessment. 5 (2019a): 028.

22. Yap CK., et al. "Heath risk assessment of heavy metals in prawn Penaeus merguiensis collected in 2007 from Sri Serdang market, Peninsular Malaysia". Acta Scientific Nutritional Health 3.8 (2019b): 109-113.

23. Yap CK., et al. "Distribution of heavy metals in edible bivalve Donax faba collected from Pasir Panjang: A health risk assessment". Frontiers in Drug, Chemistry and Clinical Research 2 (2019c): 1-5.

24. Broschat TK. "Palm Nutrition and Fertilization". HortTechnology 19.4 (2009): 690-694.

25. von Uexküll HR and Fairhurst TH. Fertilizing for High Yield and Quality. The Oil Palm. IPI Bern (1991): 79.

26. Finck A. Fertilizers and fertilization. Introduction and practical guide to crop fertilization. 2nd edition (German). Weinheim, Germany, Verlag. Chimie (1992).

27. Brady NC and RR Weil. "The Nature and Properties of Soil. Upper Saddle River". NJ Prentice Hall Inc. (2002): 690.

28. NMH (Nutrient Management Handbook). International Fertilizer Association (IFA, Paris), World Farmers' Organisation (WFO, Rome), and GACSA Facilitation Unit (Food and Agriculture Organization of the United Nations). First edition, (2016): 35 .

29. Hartley CWS. The Oil Palm. (Tropical Agriculture Series), 3rd ed. Longman Scientific \& Technical, Harlow (1988): 761.

30. Reeves JB and Weihrauch JL. Consumer and Food Economics Institute. Composition of foods: fats and oils. Agriculture handbook 8-4. Washington, D.C.: U.S. Dept. of Agriculture, Science and Education Administration (1979).

31. Mancini A., et al. "Biological and nutritional properties of palm oil and palmitic acid: Effects on health". Molecules 20.9 (2015): 17339-17361. 
32. Fairhurst TH and Mutert E. "Interpretation and Management of Oil Palm Leaf Analysis Data”. Better Crops International 13.1 (1999).

33. Fairhurst $\mathrm{T}$ and Hardter R. Oil palm. Management for large and sustainable yields. PPI/PPIC and IPI (2003).

34. Yaacob A., et al. "Assessment of health risks of the toxic $\mathrm{Cd}$ and $\mathrm{Pb}$ between leafy and fruit vegetables collected from selected farming areas of Peninsular Malaysia". Integrative Food, Nutrition and Metabolism 5.3 (2018a): 1-9.

35. Yaacob A., et al. "A comparative study of health risks of Fe and $\mathrm{Ni}$ in the vegetables collected from selected farming areas of Peninsular Malaysia". Journal of Aquatic Pollution and Toxicology 2.1 (2018b): 21.

36. Yaacob A., et al. "Health risks of essential $\mathrm{Cu}$ and $\mathrm{Zn}$ via consumption of vegetables and relationships with the habitat topsoils from three farming areas of Peninsular Malaysia". In: Soil Pollution: Sources, Management Strategies and Health Effects, Editor: Chee Kong Yap, Nova Science Publishers, New York, USA. Chapter 9 (2019): 229-260.

37. Yap CK., et al. "Heavy metals in bitter gourd (Momordica charantia): Human health risk assessment". ARC Journal of Nutrition and Growth 5.1 (2019a): 1-5.

38. Yap CK., et al. "Human health risks of heavy metals in okra (Abelmochus esculentus) and lettuce (Lactuta sativa) collected from selected farms in Peninsular Malaysia". Food Science and Nutrition Technology 4.3 (2019b): 000180.

Volume 3 Issue 12 December 2019

(C) All rights are reserved by Chee Kong Yap., et al. 